\title{
Interpretation of Verbal Humor in the Sitcom The Big Bang Theory from the Perspective of Adaptation-relevance Theory
}

\author{
Zejun Ma \\ School of Foreign Languages, Dalian University of Technology, Dalian, China \\ Man Jiang \\ School of Foreign Languages, Dalian University of Technology, Dalian, China
}

\begin{abstract}
Humor plays a very important role in every sphere of our daily life, especially verbal humor which is mainly carried by language use in a certain context to achieve humorous effect. As a special carrier of humor, sitcom, which is a type of comedy performance, has attracted millions of audiences with humorous utterances all over the world. The American sitcom The Big Bang Theory has been one of the most popular American sitcoms in China within these years which largely count on verbal humor to create general humorous effect. Based on the achievements made by previous researchers, the present study explores the verbal humor in the American sitcom The Big Bang Theory in the light of a new model-Adaptation-Relevance model so as to reveal its interpretive power of humor and its feasibility in analyzing verbal humor in the sitcom The Big Bang Theory. The paper mainly adopts the qualitative and descriptive methods to analyze the selected examples and finally comes to a conclusion that this Adaptation-Relevance model which is an integration of two powerful pragmatic theories holds the interpretive power for verbal humor and has feasibility in analyzing verbal humor by using the data in sitcom The Big Bang Theory. Also through the research it further investigates Adaptation-Relevance Theory and extends the application scope and interpretive power of this model.
\end{abstract}

Index Terms - verbal humor, adaptation-relevance theory, The Big Bang Theory

\section{INTRODUCTION}

\section{A. The Research Background}

Humor is a common phenomenon which has a vital importance in daily life especially during communication. It can be regarded as human wit as it can adjust the state of mind from fickleness to calmness and reconcile the mutual conflict into harmony. When facing problems and disputes, people with wisdom can make good use of humor to transfer adversity into happy ending. Since 400, B.C. Plato and Aristotle had paid attention to this phenomenon and conducted researches on it and many scholars have begun to bring humor research to their own theoretical fields from different backgrounds by applying the methodologies and techniques that they have learned in other fields of study such as psychology, physiology, philosophy, anthropology, sociology. Scholar Koestler (Koestler, 1993, p. 684-685) generally divides humor into "verbal humor" and "situational humor". Compared to situational humor, verbal humor takes an extremely large proportion, and most humor is presented by language in daily life. Then in recent decades, scholars of different countries have begun to study humor from different linguistic angles such as semantics, pragmatics, functional linguistics, sociolinguistics, and cognitive linguistics.

A new model-Adaptation-Relevance model, which combines two influential pragmatic theories Adaptation Theory and Relevance Theory, is raised within ten years. Researches on humor within these two theories separately have been done by some scholars, but each of these two theories has some defects when analyzing verbal humor. The new model-Adaptation-Relevance model is not simply combining those two theories together but to combine merits of each theory and overcome the demerits of each theory. The application scope of this new model still needs to be verified. This paper is intended to analyze the production and interpretation of verbal humor in the American sitcom The Big Bang Theory from the perspective of Adaptation-Relevance Theory.

The American sitcom The Big Bang Theory has been one of the most popular American sitcoms in China within these years which largely count on verbal humor to create general humorous effect. And its original material and large amount of humorous and witty dialogues make it an ideal source of data of the humor research in this paper. The language material in the sitcom is fresh and it is close to our present life.

\section{B. Purpose and Significance of the Research}

This research aims to study whether the Adaptation-Relevance model holds interpretive power for verbal humor and its feasibility in analyzing verbal humor by using the data in sitcom The Big Bang Theory to help people have a better understanding of sitcom The Big Bang Theory, and facilitate the audience's comprehension and appreciation of the 
sitcom. In the meantime, this study can further investigate the new model--Adaptation-Relevance Theory and extend the application scope and interpretive power of this model. And from the practical view, in the process of analyzing selected examples from the sitcom, people can have a new angle in interpreting humor during communication so that they can develop a better skill in communication in daily life.

\section{REVIEW OF VERBAL HUMOR}

\section{A. Definition and Classification of Humor}

People are able to laugh for something interesting no matter how different of their sex, age, country, culture and many other aspects. Humor is a universal phenomenon shared by all people. Many scholars and researchers have given definition of humor from different perspectives, but scholars still cannot give a commonly satisfactory definition of it.

From the etymological perspective, the English word "humor" came from the Latin word in ancient times which means "fluid" or "liquid" (Attardo, 1994, p. 6). McGhee(McGhee, 1979) emphasizes humor is not a characteristic of some events such as cartoons, jokes, and clowning behavior, nor is it a behavior such as laughing and smiling, he states that humor is something in our mind and not in the real world. Psychologically, "humor is essentially a masked aggression, which gives one the gratification one desperately craves (Freud. 1976, p. 299)". And Palmer thinks that "humor is everything that is actually or potentially funny and the processes by which this "funniness" occurs." (Palmer, 1994, p. 3)

Even though definitions of humor are various from different perspectives, we can find something in common: the basic and essential factors for humor to come out. That is, there must be human participants who are able to produce and interpret the funny and interesting phenomenon when "humor" occurs, and something happening must be a funny stimulus which can amuse people.

Humor is complex and there are different classifications based on different standards. And in 1993 Koestler (Koestler, 1993) gave a general classification of humor which are verbal humor and situational humor. Verbal humor is expressed through language and also created by language, while situational humor is not. Verbal humor usually conveys humor through rhetorical techniques such as sarcasm, ridicule, irony, bombast, pun, allusion and other rhetorical skills in certain context (Rong $\mathrm{Na}, 2010$ ). It produces effect on sounds, words and ideas and refers to jokes, comic verse, anecdotes, satire, the bogus proverb and nonsense verse by means of allegory. In contrast, situational humor is concerned with such comic designs as imitation, impersonation and disguise (Zou Haixia, 2012). In this paper, we mainly focus on the study of verbal humor.

\section{B. Previous Studies on Verbal Humor}

Study of humor can be traced back over two thousand years from various fields including psychology, philosophy, physiology and so on. These flourishing humor researches in turn give rise to plenty of valuable findings and theories which can be generally included into three theories - superiority theory, relief theory and incongruity theory as traditional approaches to humor study. And in the late $20^{\text {th }}$ century, humor researches have been brought into linguistic field. Freud's relief theory lays the foundation of modern linguistic research on humor, and scholars begin to focus on humor research from different linguistic angles since Raskin (Raskin, 1985) develops the Semantic Script Theory of Humor (also SSTH).

All through these years, more scholars start their humor researches from the pragmatic perspective and have made great achievements. Most of these researches are made by adopting various pragmatic theories as their theoretical frameworks including Grice's Cooperative Principle, Sperber Leech and Levinson's Politeness Principle, Austin and Searle's Speech Act Theory, Dan Sperber and Deirdre Wilson's Relevance Theory and Verschueren's Adaptation Theory. Among them, humor studies with Grice's Cooperative Principle and Sperber and Wilson's Relevance Theory are the most. Cooperative Principle is one of the most significant theories in pragmatics. Grice holds that there must be a mutually tacit understanding between the speaker and the hearer and a principle followed by both sides in order to achieve special aim in ail speech communications. (Grice, 1975) The principle is made up of the Maxim of Quality, the Maxim of Quantity, the Maxim of Relevance and the Maxim of manner. Sometimes during communication, speakers violate Cooperative Principle on purpose to create an implicature and they communicate from another angle to express meaning thus, verbal humor occurs. According to Relevance Theory, "people's communicative purpose is to seek for optimal relevance, that is, the hearer can get enough and the best contextual effect with minimal information process. When the combination of language and concrete context doesn't have relevancy and conflict occurs, humor is produced. (Zou Haixia, 2012, p. 13)" Even though each of those theories has its merits of interpreting verbal humor, they still have their demerits. It is needed to pay equally attention on both the production side and interpretation side of humor. Therefore, the paper is intended to interpret verbal humor with Adaptation-Relevance theory combining these two influential pragmatic theories which are Relevance Theory and Adaptation Theory.

\section{THEORETICAL FRAMEWORK}

As is mentioned above, Relevance Theory and Adaptation Theory are two influential and newly arising pragmatic theories. This section focuses on introducing theoretical framework of the present study including introducing these two 
theories, the new model-Adaptation-Relevance Theory and the necessity of combing the two theories.

\section{A. Relevance Theory}

Since Dan Sperber and Deirdre Wilson formally proposed Relevance Theory in their book: Relevance: Communication and Cognition in 1986, this pragmatic theory has been considered as another influential pragmatic theory adopted in the study of humor. Superficially, Relevance Theory is just the detailed elaboration of relevance principle, one of the four categories of maxims in Grice's Cooperate Principle. However, it is different from Cooperate Principle focusing on analyzing the existing main defect of Grice's communication theory, which not only defines communication too vaguely, but explains communication too poorly (Sperber and Wilson, 2001). They argue that the human mind will instinctively react to an encoded message by considering information that it conceives to be relevant to the message and they put forward their own ostensive-inferential model. According to Relevance Theory, "inferential communication and ostension are one and the same process, but seen from two different points of view: that of the communicator who is involved in ostension and that of the audience who is involved in inference (Sperber and Wilson, 2001, p. 54)". The central claim of relevance theory is that the expectations of relevance raised by an utterance are precise enough, and predictable enough, to guide the hearer towards the speaker's meaning.

Generally, the main ideas of Relevance Theory can be summarized into four aspects:

First, there are two principles of relevance: “(1) Human cognition tends to be geared to the maximization of relevance. (2) Every act of ostensive communication communicates a presumption of its own optimal relevance" (Sperber and Wilson, 2001, p. 260). The first principle is from the cognitive perspective and the second one is from the perspective of communication. And the first principle is more general and fundamental than the second one.

Second, an ostensive stimulus is optimally relevant to an audience if "(a) the ostensive stimulus is relevant enough for it to be worth the addressee's effort to process it. (b) The ostensive stimulus is the most relevant one compatible with the communicator's abilities and preference. (Sperber and Wilson, 2001, p. 270)"

Third, according to Sperber and Wilson, there are three types of contextual effects for an input:

(a) Strengthening (providing further evidence for) existing assumptions;

(b) Contradicting (providing evidence against) existing assumptions;

(c) Combining with existing assumptions to yield new contextual effects resulting from a crucial interaction between new and old information. (Sperber and Wilson, 2001, p. 109)

Finally, the degree of relevance can be assessed by two factors: contextual effect and processing effort. Relevance varies inversely with cognitive efforts: (a) Other things being equal, the greater the contextual effects, the greater the relevance; (b) Other things being equal, the greater the processing effort, the lower the relevance (Sperber and Wilson, 2001, p. 124-5).

\section{B. Adaptation Theory}

In the book Understanding Pragmatics, Verschueren defines pragmatics as "a general cognitive, social and cultural perspective on linguistic phenomena in relation to their usage in forms of behavior" (Verschueren, 2000, p. 7). Different from relevance theory, adaptation theory claims that the use of language is a kind of social behavior which has a close relationship with cognition, society and culture in people's lives. According to Adaptation Theory, using language consists of the continuous making of linguistic choices, consciously or unconsciously, for language-internal and/or language-external reasons. So communicating consists in the making of linguistic choices. The making of choices involves the following seven aspects (Verschueren, 2000, p. 55-8): 1. Choices are made at every possible level of structure. 2. Speakers do not only choose forms, they also choose strategies. 3. The processes of choice making may show any degree of consciousness. 4. Choices are made both in producing and in interpreting an utterance. 5. Once language is used, the user is under an obligation to make choices. 6. As a rule, choices are not equivalent. 7. Choices evoke or carry along their alternatives. And according to Verschueren, language has three properties which are variability, negotiability and adaptability. According to the theory, the three properties are fundamentally inseparable. Adaptability is a cognitive process and a mechanism of language use, whereas variability and negotiability are the contents of adaptation. Then, the notion of adaptability concerning its description of the regularities for linguistic use can be analyzed in the following four angles, namely, contextual correlates of adaptability, structural objects of adaptability, dynamics of adaptability, and the Salience of the adaptation process (Verschueren, 2000).

\section{Adaptation-relevance Theory}

From the introduction of these two theories above, we can get that Relevance Theory has strong explanatory power on the account of the cognitive process in communication; and Adaptation Theory can be regarded as a new theory for fully interpreting the phenomena in language use from cognitive, social, and cultural perspectives, which provides us systematic, scientific and general explanations of linguistic properties and the essence of language use. However, both of these two theories have their demerits. For Relevance Theory, it neglects the importance of social and cultural factors in the process of communication and it does not explain what the speaker's concrete relevance presumption refers to, and what the relationship between this relevance presumption and the specific context is. Besides, relevance theory places emphasis on the interpretation side and neglects the production side though both sides are equally important for successful communication. For Verschueren's Adaptation Theory, even though it has provided a satisfactory and 
adequate descriptive framework for the regularities of language use and puts equal emphasis on the utterance production and interpretation and takes the social and cultural factors into account in the process of communication, which overcomes the defects of Relevance Theory, but it does not explain how to find the objects of adaptation from various representations and why the degrees of salience in making choices are different, that is, why some choices are made very consciously and some are made almost automatically while others fall in between in terms of consciousness.

Based on overcoming the demerits of these two theories and retaining their bright and reasonable parts, a Chinese scholar Yang Ping (Yang Ping, 2001) proposed Relevance-Adaptation Model from the perspective of utterance production in 2001. But this R-A model, like most previous pragmatic researches, just focuses on the side of utterance production. Later, based on the former attempt of Yang Ping, another Chinese scholar Ran Yongping (Ran Yongping, 2004) proposed Adaptation- Relevance Model (A-R Model) in 2004 which is more feasible and powerful than R-A model and it pays attention to both the speaker's utterance production side and the hearer's interpretation side and emphasizes that communication is an interaction between the speaker and the hearer.

According to Ran Yongping, during communication, for the speaker, communication is an ostensive behavior assuring the relevance; for the hearer, communication is an inferential process of discerning the speaker's intention in order to achieve the cognitive and pragmatic effects. Therefore, language production and interpretation is a process of contextual adaptation and relevance seeking. And the main points of his theory are as follows: 1 . In Adaptation-Relevance Model communication is relevance-oriented; 2. the speaker's presumption of relevance determines his choice of a particular utterance; 3. the process of adaptation-relevance is a dynamic inter-adaptation between linguistic choices and contextual correlates; 4. the process of Adaptation-Relevance model is one of choosing strategies (Ran Yongping, 2004).

To sum up, Adaptation-Relevance Model is adequate in its descriptive and explanatory force in terms of the whole process of communication concerning both language production and interpretation. It not only puts emphasis on human's cognition, but also takes the physical, social and cultural contexts that affect the communicator's linguistic choices into account and provides a connection between relevance assumption and contextual correlates at the same time. It takes on a specific image of the relevance assumption and explains the choice of strategy involved in language use. In conclusion, the Adaptation-Relevance model affords much more powerful description and explanation force than either Relevance Theory or Adaptation Theory respectively.

\section{Analysis of Verbal Humor In the Sitcom The Big BANG Theory From the Perspective of ADAPTATION-RELEVANCE THEORY}

The sitcom is short for situation comedy and is regarded as a genre of comedy performance in which some recurring characters showing audiences a series of humorous stories in a familiar environment such as a family home, workplace, stores and so forth. It is originated in radio program, but it is mostly found on television today. For American sitcoms, the story in each episode is written to run 22 minutes in length and there are usually about 20 episodes in one season. American sitcoms are very popular these decades and they are welcomed by both teenagers and older audiences, among which the American sitcom named The Big Bang Theory is very famous and outstanding these years with six seasons. It mainly tells a series of humorous stories that happened among some ladies with distinguished characteristics and four brilliant physicists working at Caltech in Pasadena, California who are colleagues and friends working on their own work projects and spending time together playing video games, watching science-fiction movies and reading comic books. And among these four physicists, one named Sheldon Cooper is extremely different from normal people in many ways such as habits, thoughts and so on, which creates many funny stories and humorous dialogues. Here a brief analysis will be made of several pieces of humorous dialogues of these classic roles from Season Six of the sitcom from the perspective of Adaptation-Relevance Theory.

\section{A. Relevance-orientation}

\section{Example 1}

Russian astronaut: Hey, fruit loops, you got a phone call.

Wolowitz: Who is it?

Russian astronaut: A woman who says she's your mother but sounds like your father.

Wolowitz: (pick up the phone call) Hey, ma? You know, we could see each other if you turn on the computer.

Wolowitz's mother: I'm not going to near that fakakta thing. I'll catch a computer virus!

Wolowitz: You can't catch a computer virus.

Wolowitz's mother: Oh, so now you're an astronaut and a doctor? (Sohu TV, 2012: episode 1)

The background of this group of dialogue is that Wolowitz is selected as an astronaut living in space for several days, and his mother is making a space phone call with him. People who have seen the sitcom all know that his mother's voice sounds very strange like an old man. So when Wolowitz asks "Who is it?" after that Russian astronaut tells him there is a phone call for him, that Russian astronaut answered that "A woman who says she's your mother but sounds like your father." Audiences refer to that related background information after hearing that utterance and get the humorous effect. Just as Adaptation-Relevance model says that communication is relevance-oriented. Then Wolowitz tells his mother that she can use the computer to do video chat, but his mother thinks that she will catch a computer 
virus if she uses a computer which is contradictory to the fact that everybody else knows. So when audiences hear this utterance and relate to the physical fact, they find the contradiction and get the amusement.

Also, in Adaptation-Relevance Model, there are two principles of relevance: the maximal relevance and the optimal relevance. Human cognition tends to be maximally relevant and every act of ostensive communication conveys a presumption of its own optimal relevance. When there is a big difference between the maximal relevance and the optimal relevance during communication especially in comedy performances, audience will have to make a larger processing effort to understand the dialogues, but big humorous effect and amusement will be the compensation. Here's another example:

Example 2

Stuart: So, Howard's really in space, huh?

Leonard: Mm-hmm, International Space Station, 250 miles that way.

Rajesh: Right now, Howard's staring down at our planet like a tiny Jewish Greek god. Zeusowitz.

Sheldon: I must admit, I can't help but feel a twinge of envy. He can look out the window and see the majesty of the universe unfolding before his eyes -- his dim, uncomprehending eyes. It's like a cat in an airport carrying case. (Sohu TV, 2012: episode 1)

From the dialogues, we can see that these friends of Howard admire him in the space and speak highly of his experience. And when Sheldon says "I must admit, I can't help but feel a twinge of envy. He can look out the window and see the majesty of the universe unfolding before his eyes", audience will have maximal relevance that he will continue compliment Howard with beautiful words. But after a short pause, Sheldon says that "his dim, uncomprehending eyes. It's like a cat in an airport carrying case", which is a little scornful and sarcastic. Then audiences get the optimal relevance that even though Howard becomes an astronaut in space, he still looks down upon him and thinks that Howard is not qualified. The contradiction of maximal relevance and optimal relevance creates a great humor here.

\section{B. Presumption of Relevance}

According to Adaptation- Relevance Model, the speaker's presumption of relevance determines his choice of a particular utterance. Speakers and hearers both have to make choices of their own linguistic ways so as to achieve a successful communication and in the choice-making process the relevance presumption restrains their choices. For the speaker, he/ she has to choose proper linguistic forms and styles to express his / her intention clearly to the hearer; and for the interpretation side, the hearer has to make particular inference by adapting speaker's very contextual presumption to certain linguistic choices given by the speaker with enough relevance providing as the guide. Therefore, these linguistic choices play a very important role for both production side and interpretation side during communication. In sitcoms, performers rely on presumption of relevance making proper linguistic choices to pursue optimal relevance, while audiences will interpret the verbal humor produced by performers through the relevance presumption formed in their mind to understand performers' actual intention.

Example 3

Amy: Have I ever told you you're like a sexy praying mantis?

Sheldon: Every time you drink alcohol.

Amy: You know what's wonderful about the praying mantis? They devour their mate.

Sheldon: Your point being....?

Amy: (unlock the top button of her blouse) "Dessert" is served.

Sheldon: I just had cobbler. (Sohu TV, 2012: episode 1)

This dialogue happens when Amy and Sheldon have dinner together in a restaurant to celebrate their second anniversary as boy friend and girl friend. Sheldon doesn't like intimacy physical contact with other people including his girl friend Amy, while Amy doesn't like that way. So after drinking some wine, Amy tries to seduce Sheldon with the metaphor and says that "Dessert is served", but she gets the answer that "I just had cobbler", which means a rejection to her. From the dialogue, we can get that she may have the following assumptions in mind:

a) Sheldon and she are girl friend and boy friend.

b) Sheldon looks so sexy in her eyes especially after drinking alcohol.

c) She wants to have an intimacy contact with Sheldon.

d) She comes up with a metaphor that Sheldon looks like a praying mantis which devours her mate.

e) She compares herself as a dessert and tries to imply that Sheldon can "devour" her.

So after interpreting Amy's assumptions we can understand why she chooses that metaphor as her expressing linguistic forms such as "Dessert is served".

Audiences can't help laughing after watching this dialogue probably because they have the following assumptions in mind:

a) Sheldon and Amy are partners.

b) It's normal for them to have intimacy physical contact.

c) Amy tries to seduce Sheldon with a metaphor expression

d) Sheldon as a man should give related response accepting Amy's request.

e) Sheldon refuses her by choosing a convention linguist form answering her question and ignores her intention 
expressed by the metaphor.

Based on the above assumptions, audiences can get why they choose those linguistic forms during communication and interpret their intentions ending with a burst of laughter.

\section{Dynamic Process of Inter-adaptation}

Based on Adaptation- Relevance Model, the process of adaptation-relevance is a dynamic inter-adaptation between linguistic choices and contextual correlates during communication. Here contextual correlates not only refer to physical world, but also refer to mental and social context. In sitcoms, often when audiences and performers have different contextual correlates and optimal relevance, humor effect will take place.

Example 4

Stuart: Should we go?

Sheldon: Yeah, but one more question. If you're going to replace Wolowitz, I need to know little more about you.

Stuart: All right.

Sheldon: Wolowitz went to MIT (Massachusetts Institute of Technology), what's your educational background?

Stuart: I went to art school.

Sheldon: Equally ridiculous. Let's go. (Sohu TV, 2012: episode 2)

This conversation happens when Howard goes to space and Rajesh needs a company, so Raj asks Stuart to join in this little friend group, but Sheldon refuses. Then Raj and Leonard persuade Sheldon that he can regard Stuart as Wolowitz. Then Sheldon asks some questions to test how similar Stuart and Wolowitz are to each other. When Sheldon says "Wolowitz went to MIT (Massachusetts Institute of Technology), what's your educational background", we all know that MIT is an outstanding university, if Stuart wants to be accepted by Sheldon, he needs to have similar good education background with Wolowitz. But he answers in truth that he just went to art school which is not very high education background. In most audiences' mental world, Sheldon won't accept him because of his low education background. But Sheldon then says "Equally ridiculous. Let's go." This utterance indicates that in Sheldon's mental world MIT is just as bad as an art school, which is totally different from common people's thought and makes him say that they are equally ridiculous. And this contradiction and different relevance to context or the mental world creates a big humor effect to audiences.

From the brief analysis of the above example, we can get that both the production and interpretation sides of verbal humor have to take the inter-adaptation between the contextual choices and linguistic choices into account, and context is very important in the verbal humor communication.

\section{Strategy-choosing Process}

In light of Adaptation-Relevance Theory, speakers and hearers not only choose linguistic forms by adapting to the relevant contextual correlates in communication, but also choose strategies in the process of adaptation- relevance consciously or unconsciously. When they choose a certain strategy, they have to choose certain linguistic levels such as sound structure, lexicon, sentence proposition and so on to achieve a successful communication and express their true intention.

Example 5

Steven Hawking: Do you like brain teasers?

Sheldon: Oh, I love brain teasers.

Steven Hawking: What do Sheldon Cooper and a black hole have in common?

Sheldon: .......

Steven Hawking: They both suck! (Sohu TV, 2012: episode 6)

This conversation happens when Sheldon wants to make friends with the great physicist Steven Hawking by playing games through the internet. But Hawking often loses in the game, so he thinks of a way to satirize him and make him unhappy. We both know that the word "suck" has many meanings. It not only means an attraction force, but also means something or somebody is very bad or annoying. Therefore, Hawking makes good use of the meaning of lexicon and chooses this semantic ambiguity as the strategy expressing his true intention and feelings in this conversation. Also, this semantic ambiguity brings great humorous effect to audiences.

To sum up, during communication both utterance production side and interpretation side have to make linguistic choices and choose strategies to seek the optimal relevance according to their presumptions of relevance to achieve a successful communication. Conversation is filled with the process of adaptation- relevance. And based on the statement and brief analysis of the above examples, it is easy to get that to some extent sitcoms do rely on principles of Adaptation-Relevance Theory consciously or unconsciously. In turn, Adaptation-Relevance Theory does have great explanatory power and feasibility on the analysis of production and interpretation of verbal humor.

\section{CONCLUSION}

From the above analysis, it can be concluded that Adaptation-Relevance Theory does have great explanatory power and feasibility on the analysis of production and interpretation of verbal humor in the sitcom The Big Bang Theory. The whole process of producing and interpreting verbal humor in humorous conversations of sitcoms is full of the process of 
adaptation and relevance. Performers make the inter-adaptation between the linguistic choices and context choices and choose some certain strategies to seek the optimal relevance according to their presumptions of relevance to achieve a successful communication providing the amusement, relaxation and humorous effect for audiences. Also, based on the analysis of the verbal humor in the sitcom, it is obviously shown that the Adaptation-Relevance model affords much more powerful description and explanation force than either Relevance Theory or Adaptation Theory respectively.

\section{REFERENCES}

[1] Attardo, Salvatore. (1994). Linguistic Theories of Humor. Berlin \& New York: Mouton de Gruyter.

[2] Freud. (1976). Jokes and Their Relation to Unconscious. Ed. Angela Richards. London: Penguin Books.

[3] Grice, H.P. (1975). Logic and Conversation. In Cole Peter \& Jerry L. Morgan (Eds.), Syntax and Semantics. New York: Academic Press, 108.

[4] Koestler, A. (1993). Humor and Wit. Encyclopaedia Britannica. (vol. 20). Ed. Robert McHenry. Chicago: Encyclopaedia Britannica, Inc, 684-685.

[5] McGhee, Paul E. (1979). Humor and Its Development. San Francisco: W. H. Freeman and Company.

[6] Palmer, J. (1994). Taking Humor Seriously. New York: Routledge.

[7] Ran Yongping. (2004). Adaptation-Relevance Analysis in Verbal Communication. Foreign Languages Research, 117, 28-33.

[8] Raskin, V. (1985). Semantic Mechanisms of Humor. Holland: Reidel Publishing Company.

[9] Rong Na. (2010). Research on the Effects of DM's Use in Humorous Language. Changsha University of Science and Technology.

[10] Sohu TV. The Big Bang Theory Season Six. (2012). Sohu TV: http://tv.sohu.com/s2012/4402/s353901232/ (accessed 13/7/2013)

[11] Sperber, D. \& Wilson, D. (2001). Relevance: Communication and Cognition. Beijing: Foreign Language Teaching and Research Press.

[12] Verschueren, J. (2000). Understanding Pragmatics. Beijing: Foreign Languages Teaching and Research Press \& Edward Arnold Ltd.

[13] Yang Ping. (2001). Relevance-Adaptation Model. Foreign Language, 6, 21-28.

[14] Zou Haixia. (2012). A Study of Verbal Humor in Cross Talk Based on Adaptation-Relevance Model. Hunan Normal University.

Zejun Ma was born in Fuxin, China in 1970. She received her MA degree in linguistics from Dalian University of Foreign Languages, China in 2004.

She is currently an associate professor in the School of Foreign Languages, Dalian University of Technology, Dalian, China. Her research interests include Applied Linguistics, Pragmatics and Stylistics.

Man Jiang was born in Hei Longiiang, China in 1988. She got her BA degree in English from Dalian University of Technology, Dalian, China. She is currently pursuing her MA degree majoring in Foreign Linguistics and Applied Linguistics in Dalian University of Technology, China. Her research interests include Applied Linguistics, Pragmatics and Stylistics. 